\title{
Intra-oral flow patterns and speeds in a suspension-feeding fish with gill rakers removed versus intact
}

Jennifer S. Smith

S. Laurie Sanderson

College of William and Mary, slsand@wm.edu

Follow this and additional works at: https://scholarworks.wm.edu/aspubs

Part of the Marine Biology Commons

\section{Recommended Citation}

Smith, Jennifer S. and Sanderson, S. Laurie, Intra-oral flow patterns and speeds in a suspension-feeding fish with gill rakers removed versus intact (2008). Biological Bulletin, 215, 309-318.

https://scholarworks.wm.edu/aspubs/1036

This Article is brought to you for free and open access by the Arts and Sciences at W\&M ScholarWorks. It has been accepted for inclusion in Arts \& Sciences Articles by an authorized administrator of W\&M ScholarWorks. For more information, please contact scholarworks@wm.edu. 


\title{
Intra-Oral Flow Patterns and Speeds in a Suspension- Feeding Fish With Gill Rakers Removed Versus Intact
}

\author{
JENNIFER C. SMITH* AND S. LAURIE SANDERSON† \\ Department of Biology, College of William and Mary, P.O. Box 8795, Williamsburg, Virginia \\ 23187-8795
}

\begin{abstract}
Oreochromis aureus, a species of tilapia, is a suspension-feeding fish that employs a pumping action to bring water into its mouth for filtering.To address questions about water flow inside the mouth, we used a microthermistor flow probe to determine the speed of intra-oral flow during suspension feeding in this species before and after surgical removal of gill rakers. Synchronization with highspeed external videotapes of the fish and high-speed video endoscopy inside the oropharyngeal cavity allowed the first correlation of oral actions with intra-oral flow patterns and speeds during feeding. This analysis established the occurrence of a brief reversal of flow $(\approx 80$-ms duration) from posterior to anterior in the oropharyngeal cavity prior to every feeding pump (250-500-ms duration). In industrial crossflow filtration, oscillating or pulsatile flow increases filtration performance by enhancing the back-migration of particles from the region near the filter surface to the bulk flow region, thus reducing particle accumulation that can clog the filter. In endoscopic videotapes, these pre-pump reversals, as well as post-pump reversals $(\approx 500$-ms duration), were observed to lift mucus and particles from the branchial arches for subsequent transport toward the esophagus. Intra-oral flow speeds were reduced markedly after removal of the gill rakers. We hypothesize that the decrease in crossflow speed during feeding pumps following the removal of gill rakers and mucus could be due to increased loss of water between the anterior branchial arches.
\end{abstract}

Received 11 December 2007; accepted 9 September 2008.

* Present address: College of Veterinary Medicine, Virginia Polytechnic Institute and State University, Blacksburg, VA 24061.

$\dagger$ To whom correspondence should be addressed. E-mail: slsand@ wm.edu

\section{Introduction}

Vertebrate suspension feeders, such as baleen whales and many species of flamingo, duck, and fish, extract small food particles from massive volumes of water. Basic questions regarding these animals' filtration mechanisms remain unresolved, including why the filtering structures don't clog, how these animals retain particles that are small enough to pass through gaps between the filtering structures, and how captured particles are transported posteriorly to the esophagus for swallowing. To address these questions, quantitative data are needed on the movement of food particles inside the oropharyngeal cavity as well as patterns of fluid flow and flow speeds near the filtering structures.

When fish generate suction to draw water into their mouths during feeding, flow inside the oropharyngeal cavity had been assumed to be unidirectional from anterior to posterior. Callan and Sanderson (2003) presented the first endoscopic data illustrating that intra-oral flow reverses to travel briefly in a posterior-to-anterior direction when water is engulfed by fish that use a pumping action in suspensionfeeding. Filtration engineers have recently designed industrial systems to generate oscillatory or pulsatile flow over the filter surface that reduces clogging and increases filtration performance (e.g., Wang et al., 2007), but oscillatory or pulsatile flow generated by organisms has not been examined in any biological filtration system.

Intra-oral flow patterns of vertebrate species during feeding have not been analyzed quantitatively using high-speed video endoscopy synchronized with high-speed external videotapes. Thus, the oral actions that are identifiable from external videotapes of fish during feeding have not previously been correlated with the resulting intra-oral flow reversals that are quantifiable from endoscopic videotapes. Data on the relative timing of oral actions and intra-oral 
flow reversals are essential for investigating the causes and functions of these flow reversals.

Here we present the first integrated analysis of oral actions, intra-oral fluid dynamics, and intra-oral particle movement during fish feeding. Intra-oral flow patterns and flow speeds during suspension feeding are critical in determining the mechanisms by which food particles are encountered, retained, and transported within the oropharyngeal cavity. Quantification of these flow characteristics can also subsequently aid in modeling the efficiency and rate of suspension feeding (Rubenstein and Koehl, 1977; LaBarbera, 1984; Shimeta and Jumars, 1991).

Pump suspension-feeding fish generate suction to draw water into the oropharyngeal cavity during a series of feeding pumps (Lazzaro, 1987). In contrast, ram suspensionfeeding fish generate intra-oral flow by swimming forward with the mouth open (Sanderson and Wassersug, 1993). Intra-oral flow speeds have been measured for only one pump suspension-feeding fish species (Sacramento blackfish, Orthodon microlepidotus, Cyprinidae; Sanderson et al., 1991) and one ram suspension-feeding species (paddlefish, Polyodon spathula, Polyodontidae; Sanderson et al., 1994). Although Oreochromis aureus (Steindachner, 1864, Cichlidae), a species of tilapia, is a pump suspension-feeding fish, the shape of the oropharyngeal cavity and the morphology of the gill rakers are substantially different from those of Orthodon microlepidotus. Here we use data from $O$. aureus to test the hypothesis posed by Sanderson $e t$ al. (1994) that pump suspension-feeding species generate substantially higher intra-oral flow speeds during feeding than ram suspension-feeding species produce.

A number of filtration mechanisms have been proposed to explain how pump suspension-feeding tilapia separate food particles as small as $5 \mu \mathrm{m}$ from the water, allowing the particles to be swallowed while the filtrate exits posteriorly from the oropharyngeal cavity. Gill rakers, as well as minute toothed projections termed microbranchiospines, are attached to the branchial arches. The gill rakers, the microbranchiospines, or both, of tilapia have been hypothesized to form either a dead-end sieve or a hydrosol filter (Greenwood, 1953; Gosse, 1956; Whitehead, 1959; Beveridge et al., 1988; Beveridge and Baird, 2000). The two mechanisms differ in the way they capture particles. A dead-end sieve retains particles on the basis of their size in relation to the "mesh" size of the filtering structures. A hydrosol filter ("hydrosol" indicating that the particles are suspended in water) relies on hydrodynamic processes to bring particles in contact with its filtering structures and often uses adhesive properties of its filtering structures to retain particles. When particles are too large to pass between the pores of a dead-end sieve, the particles are retained on the surface of the sieve as the filtrate exits perpendicularly through the pores. In contrast, particles encounter the structural elements of a hydrosol filter due to hydrodynamic processes such as direct interception and inertial impaction, and the particles can then be retained by adhesion to the sticky surfaces of the filter, even if the particles are small enough to pass between the filter structures (Rubenstein and Koehl, 1977; LaBarbera, 1984; Shimeta and Jumars, 1991).

Despite the hypothesized importance of gill rakers and microbranchiospines in suspension-feeding fish, Drenner et al. (1987) found that surgical removal of all rakers and microbranchiospines from the arches of the tilapia Sarotherodon galilaeus did not significantly affect the size distribution of ingested particles or the efficiency of particle retention. Similarly, surgical removal of all rakers and microbranchiospines from $O$. aureus did not prevent the retention of particles during suspension feeding despite the absence of the hypothesized filtering structures and the virtual elimination of intra-oral mucus strands, sheets, and aggregates (Smith and Sanderson, 2007). These results demonstrated that, like $O$. esculentus (Sanderson et al., 2001), O. aureus uses crossflow filtration rather than deadend sieving or hydrosol filtration to retain suspended food particles inside the oropharyngeal cavity as filtrate exits between the gill rakers and between the branchial arches.

Crossflow filtration is an industrial filtration engineering technique that has been used extensively during the past 35 years for economical food and beverage processing, water purification, and biotechnology applications (Zeman and Zydney, 1996). In crossflow filtration (Fig. 1), particles are carried with the mainstream flow parallel to the surface of the filter, as filtrate exits between the filter elements (Brainerd, 2001; Sanderson et al., 2001). Thus, particles become increasingly more concentrated in the oropharyngeal cavity as the crossflow travels posteriorly toward the esophagus. In crossflow filtration, the gill rakers do not serve as a deadend sieve or as a hydrosol filter, and particles are not retained on the rakers. Rather, the hydrodynamic process of inertial lift (Eloot et al., 2004; Matas et al., 2004) contributes to the transport of particles in a radial direction away from the gill rakers and towards the midline of the oropharyngeal cavity as the particles are carried posteriorly with the crossflow (Sanderson et al., 2001; Smith and Sanderson, 2007). Crossflow filtration in O. aureus continued even after surgical removal of the gill rakers and microbranchiospines, indicating that the surfaces of the branchial arches themselves are involved in the generation of inertial lift forces (Smith and Sanderson, 2007).

Here we compare intra-oral flow patterns and speeds during crossflow filtration in $O$. aureus with all rakers and microbranchiospines removed versus intact. Although gill rakers are a prominent feature of most fish oropharyngeal cavities, the functions of rakers have not been established and the effects of raker removal on intra-oral flow patterns and speeds have not been investigated previously in any species. 


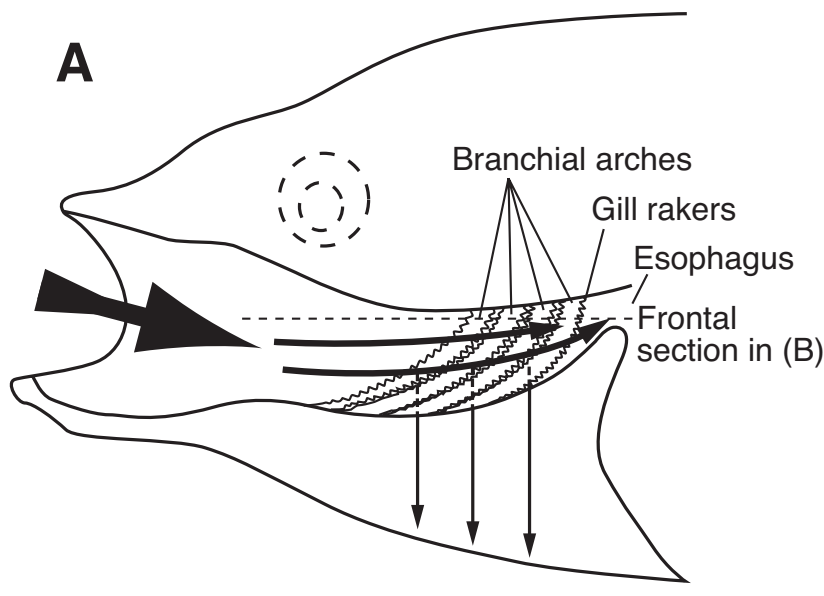

B

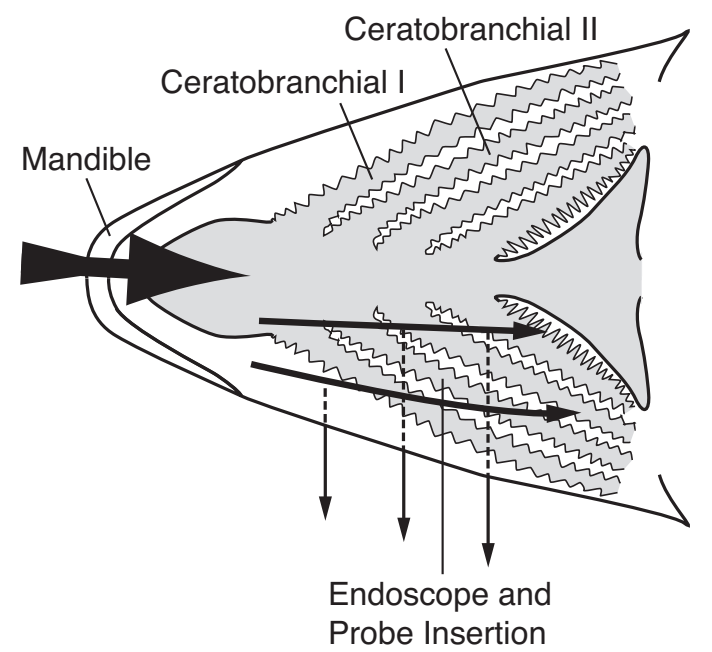

Figure 1. Anatomy and general path of water flow through the oropharyngeal cavity in Oreochromis aureus during suspension feeding. The water entering the mouth (large arrows) travels posteriorly in the crossflow (medium arrows) that is pumped along the surfaces of the branchial arches. Food particles (not shown) are concentrated in suspension and carried posteriorly with the crossflow toward the esophagus while the filtrate (small arrows) passes between the gill rakers to exit from the oropharyngeal cavity. (A) Parasagittal section showing the orientation of the branchial arches (modified from Figure 3 in Sanderson et al., 2001. Crossflow filtration in suspension-feeding fishes. Nature 412: 439-441). (B) Frontal section along the dashed line drawn in Fig. 1A, showing crossflow parallel to the floor of the oropharyngeal cavity.

\section{Materials and Methods}

\section{Endoscopy experiments}

Specimens of Oreochromis aureus were maintained on a diet of Tetramin flakes at a temperature of $25-28{ }^{\circ} \mathrm{C}$. The methods of Smith and Sanderson (2007) were used for endoscopy experiments on five specimens $(20.3-23.4-\mathrm{cm}$ standard length). The animal care procedures and experimental protocol were approved by the College of William and Mary's Institutional Animal Care and Use Committee (IACUC-406).

About $4 \mathrm{~h}$ after cannula implantation, a flexible fiberoptic endoscope (ultrathin fiberoptic type 14, 1.4-mm o.d., 1.2-m working length, $75^{\circ}$ field of view, $0.2-5.0-\mathrm{cm}$ depth of field, Olympus, New York, NY) was threaded through the cannula. The endoscope was attached to an intensified imager VSG (50-500 Hz, Kodak, San Diego, CA). An Ektapro Hi-Spec motion analyzer 1012/2 (Kodak, San Diego, CA) with split-screen imaging was used to record external views of the oral jaws simultaneously with the endoscopic views, to correlate external feeding behaviors with the movements of intra-oral structures and particles in the internal endoscopy video (Smith and Sanderson, 2007).The videotapes were analyzed frame-by-frame, using a Sony DSR-11 DVCAM video recorder with a jog shuttle (remote control unit DSRM-20, Sony, Tokyo).

Data were recorded while fish were fed a slurry of finely crushed Tetramin flakes $(0.1-1.0-\mathrm{mm}$ diameter) mixed with water. Pre-hydrated brine shrimp cysts (Artemia sp., 210$300 \mu \mathrm{m}$ ) were added to the slurry to serve as additional tracer particles when viewed through the endoscope.

\section{Gill raker and microbranchiospine removal}

The method of raker and microbranchiospine removal was modified from that of Drenner et al. (1987). Fish were anesthetized with MS-222, and the tissue supporting all lateral and medial rakers and microbranchiospines was removed with microforceps from the anterior four branchial arches on both sides of five fish (Smith and Sanderson, 2007). During the 15 days after surgery, the arches healed as described by Drenner et al. (1987) for Sarotherodon galilaeus. Endoscopy and flow-probe experiments were conducted on fish with rakers and microbranchiospines intact and again on the same individuals 15 days after removal of rakers and microbranchiospines. In the context of our experiments on $O$. aureus, we use the term "raker" in the following text to refer to both rakers and microbranchiospines.

\section{Intra-oral flow speed}

Between 1 to $24 \mathrm{~h}$ after the endoscopy experiments, a flow probe was used to measure intra-oral flow speed in three fish. The procedure was similar to that used for paddlefish in Sanderson et al. (1994). The flow probe was constructed from insulated wire $(75-\mu \mathrm{m}$ diameter, COA101, H-ML, California Fine Wire Co., Grover Beach, CA), soldered to the leads from a glass bead thermistor $(1.09-\mathrm{mm}$ diameter, Fenwal part no. 112-101BAJ-B01). The probe was temperature-compensated from 19.5 to $29.7^{\circ} \mathrm{C}$, and a calibrated speed controller was used to calibrate the probe from 0 to $185 \mathrm{~cm} \mathrm{~s}^{-1}$ in a flume. The circuit, modified from LaBarbera and Vogel (1976), was connected to an A/D 
convertor (TRX-4, Sonometrics Corporation, London, Ontario) with a sampling rate of $200 \mathrm{~Hz}$. The frequency response of the circuit with a probe of this size is about $5 \mathrm{~Hz}$ (LaBarbera and Vogel, 1976; MacIntyre, 1986; Patterson, 1991). For the circuit and probe used in this study, a 3-dB decrease in the voltage output of the circuit occurred above $10 \mathrm{~Hz}$.

For each fish specimen, the flow probe was inserted into the same cannula as was used for the endoscopic recordings. We threaded the flow probe through the cannula so that the glass bead was fully projecting into the oropharyngeal cavity (a distance of about $1.5 \mathrm{~mm}$ ). The height of the oropharyngeal cavity (i.e., the distance between the oropharyngeal roof and the branchial arches) was approximately $3 \mathrm{~mm}$ when the mouth was closed after a feeding pump had ended. Thus, the flow probe was positioned at mid-channel height. A sudden increase in flow speed marked the correct insertion point, as the flow probe was not in contact with oropharyngeal roof or branchial arch tissue at this location. This was observed through use of Sonometrics software on a personal computer to monitor the flow speed in real time. At the conclusion of the experiments, the cannula was removed under anesthesia and the implantation site healed fully.

Flow-probe signals were recorded during ventilation and suspension feeding on a slurry of Tetramin flakes and water. External videotapes were synchronized with the data from the flow probe by using a TTL-compatible trigger signal connected to the Kodak Ektapro Hi-Spec motion analyzer 1012/2 and the Sonometrics A/D convertor. From these videotapes, we were able to identify events on the flow record that corresponded with feeding activities of the fish. All video and flow data are reported as mean \pm SD unless stated otherwise. Intra-oral flow duration and intra-oral flow speed cannot be used as indicators of total volumetric flow in fish because oropharyngeal cavity shape and size change continuously throughout feeding. Consequently, volume flow rate cannot be calculated.

\section{Results}

\section{Endoscopic view}

The left ventral sections (ceratobranchials) of arches II-IV could be seen most frequently through the endoscope (Fig. 2), and the left ceratobranchial of arch I entered the field of view periodically. Prior to raker removal, the rakers were visible as projections from the arches (Fig. 2). When the endoscopy and flow-probe experiments were conducted 15 days after raker removal, there were no visible rakers or microbranchiospines. As viewed using scanning electron microscopy, the sites of gill raker removal had healed completely and the arches were smooth but undamaged.

As described below, the specific directions of water flow and particle movement recorded using the endoscope during each feeding action can be summarized as follows (Fig. 3): (1) pre-pump reversal-posterior-to-anterior flow, (2) feeding pump-anterior-to-posterior flow, (3) stage 1 of a postpump reversal-posterior-to-anterior flow, and (4) stage 2 of a post-pump reversal-anterior-to-posterior flow.

\section{Feeding pumps}

The fish used a series of pumping actions to generate suction during suspension feeding. During each feeding pump, water carrying suspended particles entered the mouth and flowed in an anterior-to-posterior direction through the oropharyngeal cavity until exiting via the operculum. External video corresponded to the internal oral movements. During a pump, the mandible abducted, the premaxillae protruded, and the hyoid abducted. Viewed simultaneously through the endoscope, the distance between the ceratobranchials and the oropharyngeal roof increased, signifying abduction of the branchial arches. After opercular abduction, the mandible, premaxillae, hyoid, and finally the opercula were adducted. Completion of this adduction was concurrent with the return of the arches to their original position. Feeding behavior after raker removal did not differ from feeding behavior before raker removal.

\section{Pre-pump reversals}

A brief posterior-to-anterior flow occurred prior to every feeding pump, as evidenced in the endoscopic videotapes when all of the suspended particles traveled with the water from posterior to anterior inside the oropharyngeal cavity (see Video A, http://www.biolbull.org/supplemental/). We term this previously unreported phenomenon a "pre-pump" reversal. These reversals were recorded before as well as after raker removal. From endoscopy footage $(125 \mathrm{~Hz})$ of each of three fish prior to raker removal, 10 pre-pump reversals were analyzed during feeding. The duration of the pre-pump reversal, measured from the time a particle began to travel in a posterior-to-anterior direction until the same particle was seen to resume anterior-to-posterior flow, was $10 \pm 3$ frames (about $80 \mathrm{~ms}$ ). A pre-pump reversal frequently dislodged and lifted attached mucus off the arches, and the subsequent pump transported the mucus posteriorly (see Video B, http://www.biolbull.org/supplemental/).

The onset of mandibular abduction was defined as occurring in the first frame of the external videotape in which the oral jaws could be observed to move in the direction of mouth opening. Thus, water could not enter the mouth until several frames after the onset of mandibular abduction because the oral jaws were still closed. Pre-pump reversals began most frequently $(43.3 \% \pm 6 \%)$ in the same video frame that the mandible began to abduct for a feeding pump (Fig. 3). However, $33.3 \% \pm 25 \%$ of the pre-pump reversals began $4 \pm 2$ frames (about $30 \mathrm{~ms}$ ) before the mandible was observed to abduct, and $20.0 \% \pm 17 \%$ of the pre-pump 


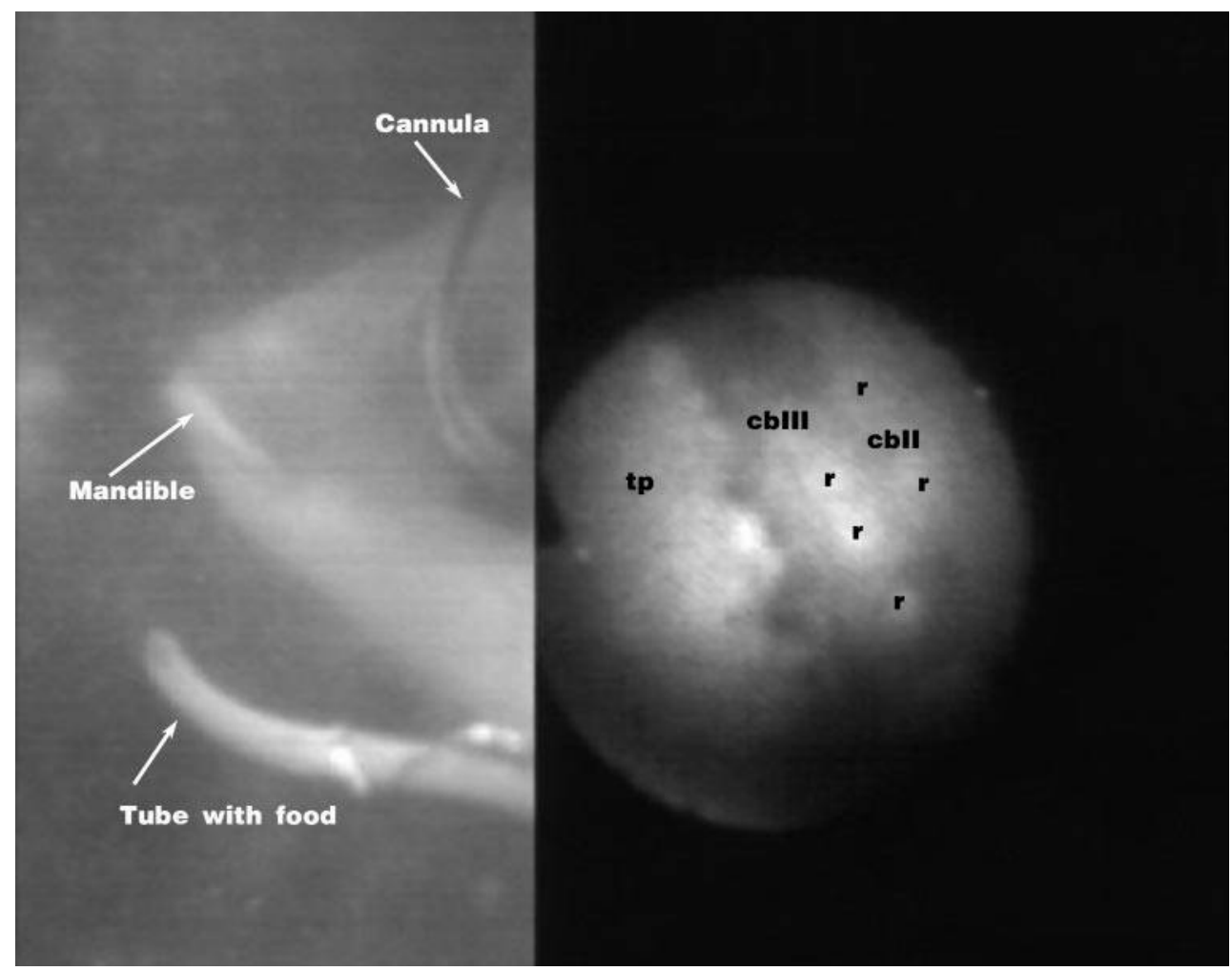

Figure 2. Split-screen video frame taken from DVCAM videotape recorded at $125 \mathrm{~Hz}$, showing external view of fish (left) synchronized with endoscopic view (right). The anterior of the fish is at the bottom right of the endoscopic image and at the left in the external view. The cannula through which the endoscope is inserted can be seen at the right of the external view. The portion of the ceratobranchial III that can be seen in this image is about $2 \mathrm{~cm}$ in length. (tp = tissue pad on oropharyngeal roof, $\mathrm{cb}$ II $=$ ceratobranchial II, cb III = ceratobranchial III, $\mathrm{r}=$ raker.) Supplementary video clips can be viewed at http://www.biolbull.org/supplemental/.

reversals began $4 \pm 5$ frames after the mandible began to abduct. Rarely, the external view of the mouth was obscured due to food particles in the water $(3.3 \% \pm 6 \%)$, making the correlation of the endoscopic view and the external view impossible.

\section{Post-pump reversals}

In feeding before and after raker removal, the anteriorto-posterior intra-oral flow during a pump was frequently followed by a reversal of flow observed through the endoscope (Smith and Sanderson, 2007). This posterior-to-anterior intra-oral flow was termed stage 1 of a reversal in endoscopic studies of O. niloticus (Sanderson et al., 1996). In the external videotapes of $O$. aureus, stage 1 was characterized by closed oral jaws, protruded premaxillae, abducted hyoid, and adducted opercula. Through the endoscope, this flow reversal was accompanied by a marked abduction of the branchial arches. After this the premaxillae retracted, the hyoid adducted, and the opercula abducted, signifying stage 2 of a reversal as defined by Sanderson $e t$ al. (1996). During stage 2, all of the suspended particles in the endoscopic videotapes of specimens of $O$. aureus resumed an anterior-to-posterior flow inside the oropharyngeal cavity. Here we refer to the combination of stage 1 and stage 2 as a "post-pump" reversal because these actions occurred immediately after a pump or immediately after another post-pump reversal, and are therefore distinct from the pre-pump reversals described above (see Video C, http:// www.biolbull.org/supplemental/).

There were no observable differences in the number of sequential feeding pumps or in the frequency of post-pump reversals during suspension feeding in the presence versus the absence of rakers. A typical bout of suspension feeding in $O$. aureus involved two to five sequential pumps at a rate of 1-2 pumps per second, followed by a single post-pump reversal. At the onset of feeding or when food concentration was increased, the rate of suspension feeding increased, with a pump being directly followed by a post-pump reversal and then another pump. This pattern repeated until the fish was satiated or until food concentration decreased again.

Using synchronous internal endoscopy and external video, analysis of seven post-pump reversals was completed 


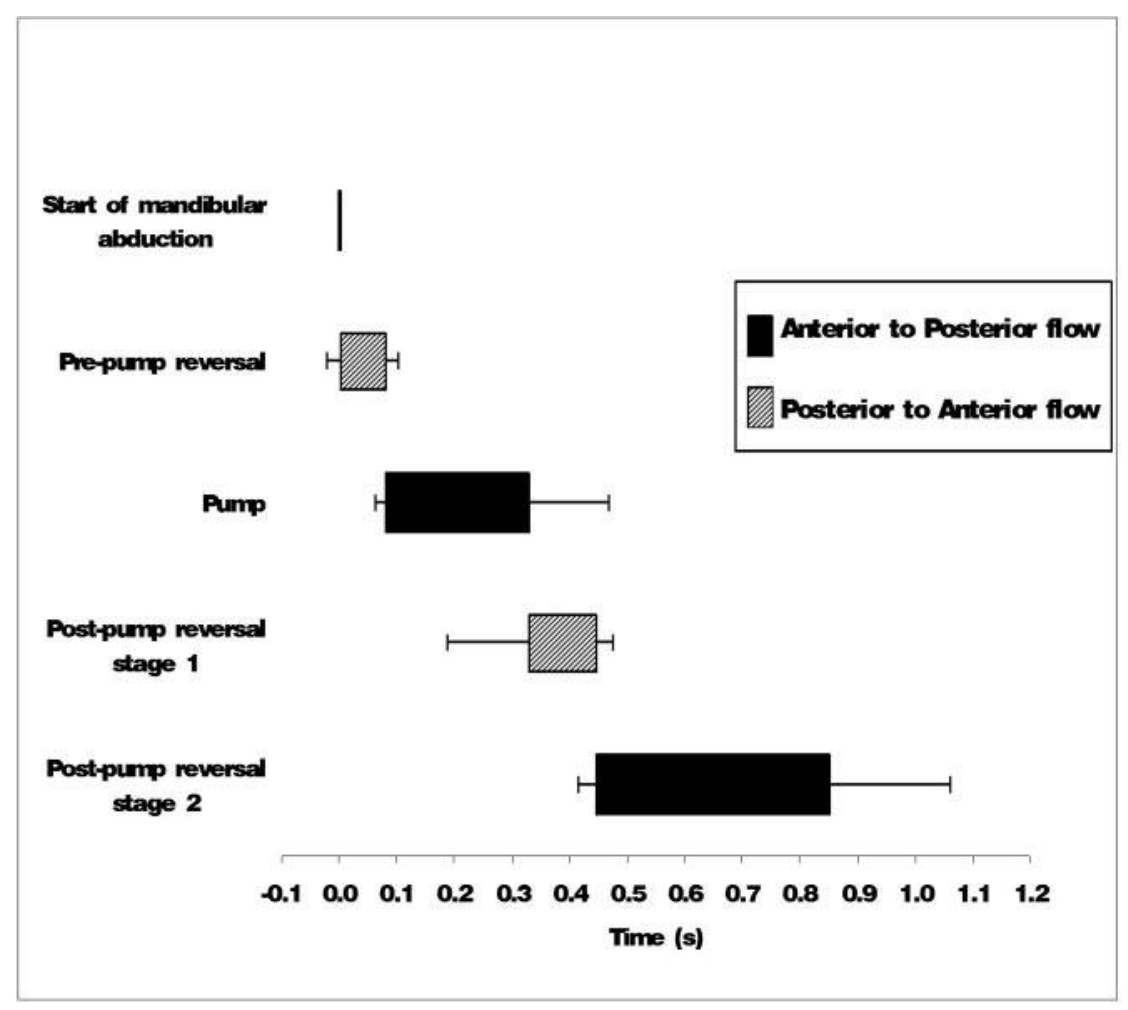

Figure 3. Diagram summarizing sequence and duration of intra-oral flow patterns recorded using the endoscope during Oreochromis aureus suspension feeding. Error bars indicate SD, $n=3$ individuals.

for each of three individuals prior to raker removal. Slurry particles or brine shrimp cysts were followed through the endoscopic field of view for the duration of each post-pump reversal, and the numbers of frames that the particles traveled from posterior to anterior (stage 1) and from anterior to posterior (stage 2) were calculated. In all three individuals, the mean duration of stage 1 of post-pump reversals was shorter than the mean duration of stage $2(15 \pm 3$ frames $\approx 120 \mathrm{~ms}$ versus $51 \pm 28$ frames $\approx 410 \mathrm{~ms}$, respectively, $125 \mathrm{~Hz}$ ), but this difference was not statistically significant at $P=0.05$ (Student's $t$-test, $\mathrm{DF}=4, P=0.08$ ).

\section{Intra-oral flow speed}

During the experiments, the fish maintained a steady position in the water column and exhibited a pattern of feeding pumps and post-pump reversals that was consistent with typical feeding behavior. Recordings of flow speed began during ventilation and continued for about $100 \mathrm{~s}$ of suspension feeding. In all recordings before and after rakers were removed, ventilation, feeding pumps, and post-pump reversals each had a distinctive flow pattern (Fig. 4). At the onset of feeding, a repeating pattern of a single pump followed by a post-pump reversal began.

Thermistor flow probes quantify flow speed rather than directionality. The peaks labeled as post-pump reversals in
Figure 4 were identified conclusively because these peaks were recorded synchronously with the oral movements of post-pump reversals (Sanderson et al., 1996) that were observed in the external videotapes. These oral movements were synchronous with the posterior-to-anterior particle movements (stage 1) and anterior-to-posterior particle movements (stage 2) of post-pump reversals in the endoscopic videotapes. With a frequency response of about $5 \mathrm{~Hz}$, the flow probe was unable to consistently resolve flow reversals having durations of about $100 \mathrm{~ms}$. Consequently, pre-pump reversals and stage 1 of post-pump reversals were usually not distinct in the recordings from the thermistor flow probe.

For each of three fish, the peak values of 15 feeding pumps and 15 post-pump reversals were analyzed for all sequences recorded before and after raker removal to determine mean speed of peak flow. The mean duration of the feeding pumps recorded by the thermistor flow probe was similar before and after raker removal, as was the mean duration of the post-pump reversals (Table 1). However, the mean peak flow speed of the post-pump reversals was almost twice as high as that of the pumps, before raker removal (paired $t$-test, $t=5.59, \mathrm{DF}=2, P=0.03$ ) as well as after raker removal (paired $t$-test, $t=3.92, \mathrm{DF}=2, P=$ 0.06). The mean peak flow speeds recorded with rakers 


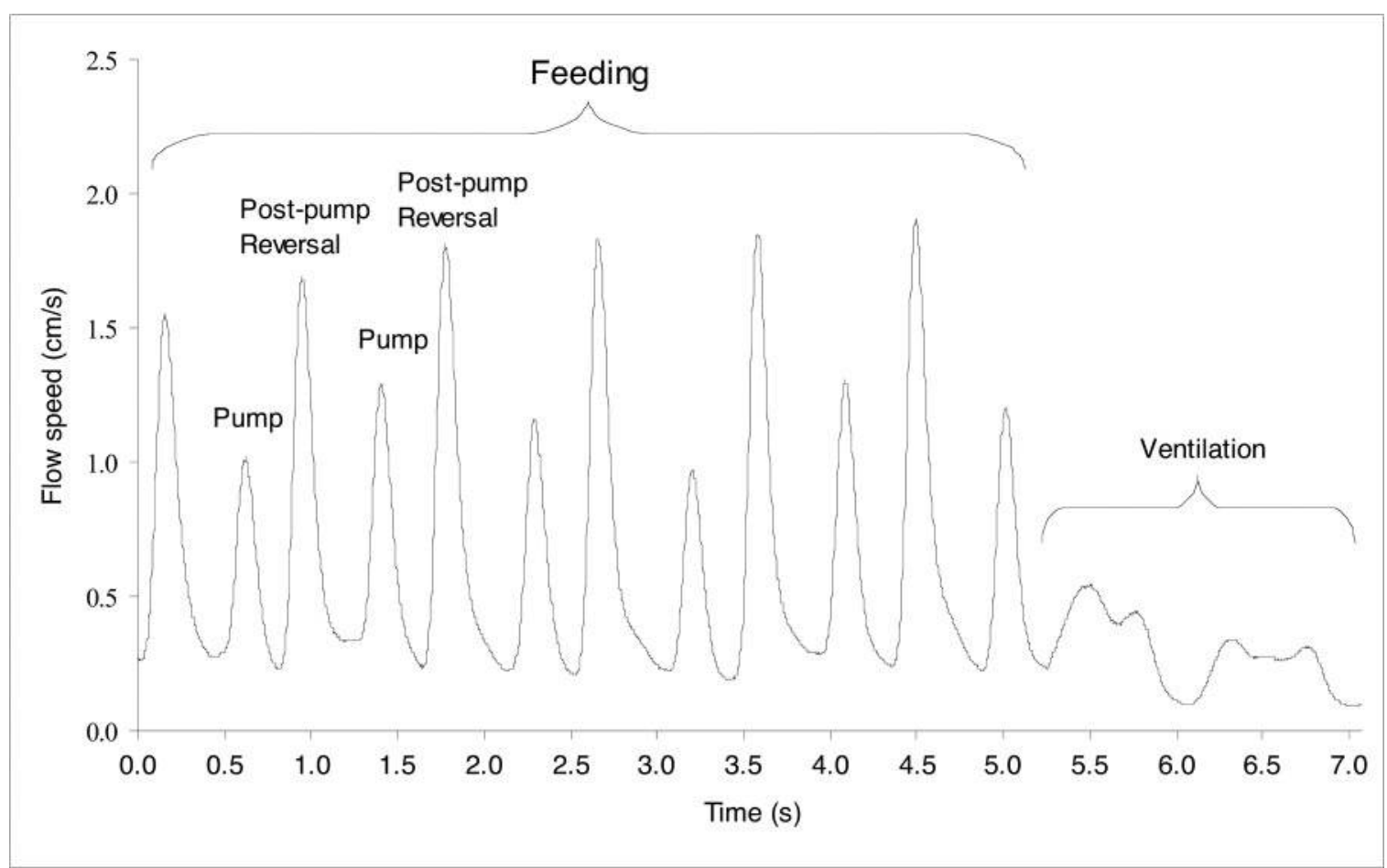

Figure 4. Representative intra-oral flow patterns and speeds recorded by a thermistor flow probe during ventilation and suspension feeding in Oreochromis aureus after removal of gill rakers.

removed were significantly less than those recorded with rakers intact for pumps (paired $t$-test, $t=6.24, \mathrm{DF}=2, P=$ 0.02 ) and for post-pump reversals (paired $t$-test, $t=7.38$, $\mathrm{DF}=2, P=0.02)($ Table 1$)$.

\section{Discussion}

\section{Functions of oral feeding actions}

The oral and opercular movements that characterize a post-pump reversal in suspension-feeding fish are clearly distinguishable from the external movements that are associated with a feeding pump (Sanderson et al., 1996). The external movements and endoscopic particle movements observed in Oreochromis aureus during stage 1 and stage 2 of reversals after a feeding pump or after another post-pump reversal were similar to those observed in $O$. niloticus and $O$. esculentus (Sanderson et al.,
1996; Goodrich et al., 2000). The duration of a feeding pump was similar for $O$. niloticus and $O$. aureus (about $0.3 \mathrm{~s}$ for both species). The mean duration of stage 1 of a postpump reversal was also similar in $O$. niloticus (about $0.10 \mathrm{~s}$, Sanderson et al., 1996) and O. aureus (0.12 s), as determined by endoscopy.

Sanderson et al. (1996) hypothesized that during feeding in $O$. niloticus, stage 1 of a post-pump reversal served to lift the mucus off the arches in preparation for transport to the esophagus during stage 2 of a post-pump reversal. Postpump reversals were the most common action during which mucus was lifted from the arches (stage 1) and carried posteriorly (stage 2 ) in both $O$. niloticus and $O$. aureus. In $65 \%$ of 23 total occurrences of mucus lifting during feeding in O. aureus (Smith and Sanderson, 2007) and $63 \%$ of 59 total occurrences of mucus lifting in $O$. niloticus (Sanderson et al., 1996), mucus that had previously been attached to the

Table 1

Duration and peak intra-oral flow speed of pumps and post-pump reversals during suspension feeding in Oreochromis aureus

\begin{tabular}{lcccc}
\hline \hline Raker condition & Duration of pump (s) & Duration of reversal (s) & Pump peak speed $\left(\mathrm{cm} \mathrm{s}^{-1}\right)$ & ${\text { Reversal peak speed }\left(\mathrm{cm} \mathrm{s}^{-1}\right)}$ \\
\hline Intact & $0.50 \pm 0.10$ & $0.55 \pm 0.10$ & $6.7 \pm 2.8$ & $11.2 \pm 3.2$ \\
Removed & $0.49 \pm 0.10$ & $0.59 \pm 0.10$ & $2.6 \pm 1.6$ & $4.9 \pm 2.8$ \\
\hline
\end{tabular}

Durations and flow speeds were recorded by a thermistor flow probe (mean $\pm \mathrm{SD}, n=3$ individuals). 
arches was lifted from the arches during stage 1 of a post-pump reversal and left the field of view during stage 2 of a post-pump reversal.

In $O$. aureus, post-pump reversals and pre-pump reversals had a similar function. Through the endoscope, a prepump reversal was visible at the beginning of every feeding pump in $O$. aureus. Mucus that was attached to the arches was often dislodged and lifted from the arches during a pre-pump reversal, while the subsequent pump transported the mucus posteriorly. However, mucus was not lifted during a pre-pump reversal as often as during a post-pump reversal (35\% versus $65 \%$ of 23 total occurrences of lifting of mucus in $O$. aureus). The report that feeding pumps were responsible for $37 \%$ of the total occurrences of lifting of mucus in O. niloticus (Sanderson et al., 1996) may have been the result of videotaping at $30 \mathrm{~Hz}$ rather than $125 \mathrm{~Hz}$, since pre-pump reversals occur too rapidly to be detected reliably at an imaging rate of $30 \mathrm{~Hz}$. Endoscopic videotapes at $125 \mathrm{~Hz}$ will be necessary to determine whether pre-pump reversals rather than feeding pumps cause mucus to lift from the arches in O. niloticus, as in O. aureus.

An ongoing goal of industrial crossflow filtration engineering is to minimize the concentration of particles that are near the filter surface or that have deposited onto the filter, because such particle buildup reduces the flux of fluid through the filter. One solution is the use of oscillating or pulsatile crossflow to create a pattern of small flow reversals, or accelerating and decelerating crossflow, which reduces particle deposition on the filter and thereby increases filtration efficiency. Flow oscillations or pulsations increase crossflow filtration performance by destabilizing the concentration polarization boundary layer over the filter surface and by increasing the back-migration of particles from the region near the filter surface to the bulk flow region (Winzeler and Belfort, 1993; Li et al., 1998; Al-Bastaki and Abbas, 2001; Hilal et al., 2005; Wang et al., 2007).

The pre-pump and post-pump reversals that lift mucus from the arches during feeding in $O$. aureus are comparable to the oscillatory or pulsatile flows that serve to improve the performance of industrial crossflow filtration. Also, pulsatile flow in industry over wall irregularities that resemble the furrows produced by gill rakers and branchial arches has been reported to generate minute vortices that enhance fluid exchange between the region near the filter surface and the mainstream flow, thereby disrupting the boundary layer over the filter surface and reducing particle accumulation near or on the filter surface (Sobey, 1980; Stairmand and Bellhouse, 1985; Nishimura et al., 2004). Swirling of particles was observed through the endoscope when transitions in flow direction occurred during $O$. aureus feeding, suggesting that there is substantial vortex-mixing during such transitions. However, the generation of small-scale vortices between arches and rakers cannot be assessed using current endoscopic technology.
The industrial filtration engineering techniques that are mentioned above serve to reduce but not eliminate particle buildup on the filter. Fouling of the filter due to particle accumulation during industrial crossflow filtration is a common problem that is responsible for the major portion of the operating cost (Espinasse et al., 2002). In contrast, during crossflow filtration in suspension-feeding fish, particles rarely contact the filter surface and do not accumulate on the filter (Sanderson et al., 2001). Quantification of pre- and post-pump reversals in fish and the associated particle transport will allow comparisons of biological versus industrial crossflow filtration mechanisms and will aid in identifying the features of fish crossflow filtration that prevent particle accumulation on the filter surface.

\section{Pre-pump reversals}

Our data indicate that the pre-pump reversal observed during suspension feeding in $O$. aureus results from the negative pressure that is generated as the hyoid and associated branchial arches begin to abduct at the onset of a feeding pump. This suction appears to draw water anteriorly from the posterior oropharyngeal cavity prior to the anterior-to-posterior flow that is established when the oral jaws open. Viewed through the endoscope, the pre-pump reversal of suspended particles inside the oropharyngeal cavity began as the branchial arches started to abduct. This is consistent with synchronous endoscopy and external video showing a posterior-to-anterior intra-oral movement of suspended particles slightly before or simultaneous with the first frame in which mandibular abduction was observed in $76 \%$ of the pumps examined.

Our report of a pre-pump reversal is not consistent with the results of Callan and Sanderson (2003), who recorded from a fiberoptic endoscope at $125-500 \mathrm{~Hz}$ and concluded that a brief $(\approx 89 \mathrm{~ms})$ post-pump reversal occurred after 96\% of the pumps during feeding in carp (Cyprinus carpio). However, with our synchronized endoscopic and external video, we can state conclusively that the brief reversal in $O$. aureus always occurred pre-pump rather than post-pump. In $O$. aureus, brief ( $\approx 80 \mathrm{~ms}$ ) pre-pump reversals were visible through the endoscope at the beginning of every pump regardless of whether the pump followed another pump or followed stage 2 of a post-pump reversal. Brief post-pump reversals were never observed in $O$. aureus, not even between a pump and stage 1 of a reversal. Because carp lack stage 1 and stage 2 reversals, observations such as these could not be used by Callan and Sanderson (2003) to determine whether the brief reversal occurred before or after each pump in carp. To establish whether the post-pump reversals reported previously in carp were actually prepump reversals, synchronous endoscopic and external videos will be needed of feeding pumps in carp that are 
preceded or followed by actions other than feeding pumps (e.g., food processing or coughing).

Pre-pump reversals were not evident in endoscopy video $(30 \mathrm{~Hz})$ recorded previously during suspension feeding in O. niloticus and O. esculentus (Goodrich et al., 2000; Sanderson et al., 1996). At a recording speed of $30 \mathrm{~Hz}$, one video frame represents about $33 \mathrm{~ms}$ of action. In the previous studies on $O$. niloticus and $O$. esculentus, lack of a highspeed intensified imager would have prevented detection of the brief pre-pump reversal, which had an average duration of $80 \mathrm{~ms}$ in $O$. aureus. A reversal in the direction of travel of individual particles cannot be tracked reliably in only one or two frames because particles often swirl or travel in slightly curved paths during the transitions between postpump reversals, pre-pump reversals, and feeding pumps. We recorded endoscopic videotapes of suspension feeding in $O$. aureus using an intensified imager at a much higher number of frames per second $(125-500 \mathrm{~Hz})$, and were thus able to establish the occurrence of a pre-pump reversal for the first time during feeding in fish.

\section{Intra-oral flow}

The mean peak flow speeds of both feeding pumps and post-pump reversals were significantly lower after raker removal than with rakers intact (Table 1). Removal of rakers may reduce resistance to water flow between the arches, resulting in a greater volume of water exiting from the oropharyngeal cavity between the anterior arches during pumps. In the absence of the obstacles presented by the rakers, a larger volume of flow passing between the arches may result in less crossflow parallel to the arches, causing lower flow speeds to be recorded in the oropharyngeal cavity during pumps. In addition, the removal of rakers led to an almost complete lack of mucus, which has been hypothesized to result in less regulation of flow between the arches (Smith and Sanderson, 2007). The reduced speed of the crossflow would be expected to reduce the inertial lift force within the oropharyngeal cavity. This could be related to the reduction of particle retention efficiency in $O$. aureus after raker removal (J. Smith and S. Sanderson, unpubl. data).

The consistent decrease in post-pump reversal flow speed after raker removal may be the result of flow reversing between the arches from the opercular cavities into the oropharyngeal cavity when negative pressure in the oropharyngeal cavity creates posterior-to-anterior flow within the oropharynx. With larger gaps between the arches in the absence of rakers, flow into the oropharyngeal cavity from the opercular cavities during a post-pump reversal could partially equalize the negative pressure in the oropharyngeal cavity, resulting in a reduced speed of intra-oral flow past the probe.

Suspension-feeding fish species are either ram suspension feeders or pump suspension feeders (Sanderson and Wassersug, 1993). Due to the importance of flow speed in affecting particle encounter and retention (Rubenstein and Koehl, 1977; Shimeta and Jumars, 1991), there has been interest in knowing whether these two categories of fish differ in the magnitudes of the flow speeds generated during feeding. Ram suspension-feeding fish such as basking sharks and anchovies engulf water by swimming forward with an open mouth. In contrast, pump suspension-feeding fish such as goldfish and carp generate suction to draw water into their mouth, and therefore have the potential to generate much higher intra-oral flow speeds.

On the basis of the mean peak flow speeds recorded in the oropharyngeal cavity of the ram suspension-feeding paddlefish (Sanderson et al., 1994), the pump suspension-feeding Sacramento blackfish (Sanderson et al., 1991), and the pump suspension-feeding bream (Hoogenboezem et al., 1991), Sanderson et al. (1994) hypothesized that pump suspension-feeding species in general operate at substantially higher flow speeds than ram suspension-feeders. However, the results reported here for $O$. aureus do not support this hypothesis, because the mean peak intra-oral flow speed generated using suction during pump suspension feeding in $O$. aureus was much lower than that reported in the other three suspension-feeding species above for which data are available. There are substantial intra-oral morphological differences between the members of the family Cyprinidae (e.g., Sacramento blackfish and bream) and the members of the family Cichlidae (e.g., O. aureus and other species in the genus Oreochromis). Our flow-speed data from $O$. aureus suggest that oropharyngeal cavity morphology and the associated fluid dynamics may be more important than method of suspension feeding (ram versus pump suspension feeding) in determining intra-oral flow speed.

Intra-oral flow data from additional species in the 12 families of suspension-feeding fish will be necessary to identify general trends relating oropharyngeal cavity morphology, the associated fluid dynamics, and intra-oral flow speed. For example, post-pump reversals have not been reported in Sacramento blackfish or bream. Post-pump reversals could compensate for the low flow speed in $O$. aureus compared to Sacramento blackfish and bream by enhancing back-migration of particles into the crossflow (Winzeler and Belfort, 1993) and thereby increasing the retention of suspended particles inside the oropharyngeal cavity. This could represent a functional trade-off that exchanges (a) a slit-like oropharyngeal cavity and repetitive pumping with a high flow speed along grooves on the oropharyngeal roof during feeding in Sacramento blackfish (Sanderson et al., 1991, 1998) for (b) an oropharyngeal cavity with a larger volume and slower flow speed with reversals for the dual functions of mouthbrooding and feeding in Oreochromis. Further study is needed to determine whether the churning that occurs during mouthbrooding 
(Keenleyside, 1991) is comparable in kinematics and function to the post-pump reversals that occur during suspension feeding in Oreochromis species.

\section{Acknowledgments}

P. Heideman, G. Capelli, and three anonymous reviewers provided valuable comments on the manuscript. We also thank K. Fitzsimmons (University of Arizona) for assistance in obtaining specimens, S. Mangalam (Tao Systems) and M. Patterson for assistance in flow-probe calibration, $\mathrm{R}$. Drenner and D. Hambright for advice on gill raker removal, and S. Bottorff, R. Broughton, T. Callan, A. Herradura, T. Huber, M. Mirabella, and D. Suskin for data collection and analysis. This research was supported by NSF grant IBN0131293 and a grant from the Thomas F. Jeffress and Kate Miller Jeffress Memorial Trust to S. L. Sanderson.

\section{Literature Cited}

Al-Bastaki, N., and A. Abbas. 2001. Use of fluid instabilities to enhance membrane performance: a review. Desalination 136:255-262.

Beveridge, M. C. M., and D. J. Baird. 2000. Diet, feeding and digestive physiology. Pp. 59-87 in Tilapias: Biology and Exploitation, M. C. M. Beveridge and B. J. McAndrew, eds. Kluwer Academic Publishers, Dordrecht

Beveridge, M. C. M., M. R. P. Briggs, A. Mowat, M. E. Northcott, and L. G. Ross. 1988. The function of microbranchiospines in tilapias. Pp. 311-317 in The Second International Symposium of Tilapia in Aquaculture: ICLARM Conference Proceedings, Vol. 15, R. S. V. Pullin, T. Bhukaswan, K. Tonguthai, and J. L. Maclean, eds. Department of Fisheries, Bangkok, Thailand and International Center for Living Aquatic Resources Management, Manila, Philippines.

Brainerd, E. L. 2001. Caught in the crossflow. Nature 412: 387-388.

Callan, W. T., and S. L. Sanderson. 2003. Feeding mechanisms in carp: crossflow filtration, palatal protrusions and flow reversals. J. Exp. Biol. 206: $883-892$.

Drenner, R. W., G. L. Vinyard, K. D. Hambright, and M. Gophen. 1987. Particle ingestion by Tilapia galilaea is not affected by removal of gill rakers and microbranchiospines. Trans. Am. Fish. Soc. 116: $272-276$.

Eloot, S., F. De Bisschop, and P. Verdonck. 2004. Experimental evaluation of the migration of spherical particles in three-dimensional Poiseuille flow. Phys. Fluids. 16: 2282-2293.

Espinasse, B., P. Bacchin, and P. Aimar. 2002. On an experimental method to measure critical flux in ultrafiltration. Desalination 146: 91-96.

Goodrich, J. S., S. L. Sanderson, I. E. Batjakas, and L. S. Kaufman. 2000. Branchial arches of suspension-feeding Oreochromis esculentus: sieve or sticky filter? J. Fish Biol. 56: $858-875$.

Gosse, J. P. 1956. Dispositions speciales de l'appareil branchial des Tilapia et Citharinus. Ann. Soc. R. Zool. Belg. 86: 303-308.

Greenwood, P. H. 1953. Feeding mechanism of the cichlid fish, Tilapia esculenta Graham. Nature 172: 207-208.

Hilal, N., O. O. Ogunbiyi, N. J. Miles, and R. Nigmatullin. 2005. Methods employed for control of fouling in MF and UF membranes: a comprehensive review. Sep. Sci. Technol. 40: 1957-2005.

Hoogenboezem, W., J. G. M. van den Boogaart, F. A. Sibbing, E. H. R. R. Lammens, A. Terlouw, and J. W. M. Osse. 1991. A new model of particle retention and branchial sieve adjustment in filter-feeding bream (Abramis brama) (Cyprinidae). Can. J. Fish. Aquat. Sci. 48: 7-18.
Keenleyside, M. H. A. 1991. Parental care. Pp. 191-208 in Cichlid Fishes: Behavior, Ecology and Evolution, M. H. A. Keenleyside, ed. Chapman and Hall, London.

LaBarbera, M. 1984. Feeding currents and particle capture mechanisms in suspension feeding animals. Am. Zool. 24: 71-84.

LaBarbera, M., and S. Vogel. 1976. An inexpensive thermistor flowmeter for aquatic biology. Limnol. Oceanogr. 21: 750-756.

Lazzaro, X. 1987. A review of planktivorous fishes: their evolution, feeding behaviours, selectivities and impacts. Hydrobiologia 146: 97-167.

Li, H., C. D. Bertram, and D. E. Wiley. 1998. Mechanisms by which pulsatile flow affects cross-flow microfiltration. AIChE J. 44: 1950-1961.

MacIntyre, S. 1986. A flow-measuring system for use in small lakes. Limnol. Oceanogr. 31: 900-906.

Matas, J.-P., J. F. Morris, and E. Guazzelli. 2004. Inertial migration of rigid spherical particles in Poiseuille flow. J. Fluid Mech. 515: 171-195.

Nishimura, T., Y. N. Bian, and K. Kunitsugu. 2004. Mass-transfer enhancement in a wavy-walled tube by imposed fluid oscillation. AIChE J. 50: 762-770.

Patterson, M. R. 1991. The effects of flow on polyp-level prey capture in an octocoral, Alcyonium siderium. Biol. Bull. 180: 93-102.

Rubenstein, D. I., and M. A. R. Koehl. 1977. The mechanisms of filter feeding: some theoretical considerations. Am. Nat. 111: 981-994.

Sanderson, S. L., and R. Wassersug. 1993. Convergent and alternative designs for vertebrate suspension feeding. Pp. 37-112 in The Skull, Vol. 3, Functional and Evolutionary Mechanisms, J. Hanken and B. K. Hall, eds. The University of Chicago Press, Chicago.

Sanderson, S. L., J. J. Cech, Jr., and M. R. Patterson. 1991. Fluid dynamics in suspension-feeding blackfish. Science 251: 1346-1348.

Sanderson, S. L., J. J. Cech, Jr., and A. Y. Cheer. 1994. Paddlefish buccal flow velocity during ram suspension feeding and ram ventilation. J. Exp. Biol. 186: 145-156.

Sanderson, S. L., M. C. Stebar, K. L. Ackermann, S. H. Jones, I. E. Batjakas, and L. Kaufman. 1996. Mucus entrapment of particles by a suspension-feeding tilapia (Pisces: Cichlidae). J. Exp. Biol. 199: 1743-1756.

Sanderson, S. L., M. E. Mort, and J. J. Cech, Jr. 1998. Particle retention by non-suspension-feeding cyprinid fishes. Can. J. Fish. Aquat. Sci. 55: 861-868.

Sanderson, S. L., A. Y. Cheer, J. S. Goodrich, J. D. Graziano, and W. T. Callan. 2001. Crossflow filtration in suspension-feeding fishes. Nature 412: 439-441.

Shimeta, J., and P. A. Jumars. 1991. Physical mechanisms and rates of particle capture by suspension-feeders. Oceanogr. Mar. Biol. Аnпи. Rev. 29: 191-257.

Smith, J. C., and S. L. Sanderson. 2007. Mucus function and crossflow filtration in a fish with gill rakers removed versus intact. $\underline{\text { J. Exp. Biol. }}$ 210: $2706-2713$.

Sobey, I. J. 1980. On flow through furrowed channels. Part 1. Calculated flow patterns. J. Fluid Mech. 96: 1-26.

Stairmand, J. W., and B. J. Bellhouse. 1985. Mass transfer in a pulsating turbulent flow with deposition onto furrowed walls. Int. J. Heat Mass Tran. 27: 1405-1408.

Wang, W., C. D. Bertram, and D. E. Wiley. 2007. Effects of collapsible-tube-induced pulsation vigour on membrane filtration performance. J. Membr. Sci. 288: 298-306.

Whitehead, P. J. 1959. Feeding mechanism of Tilapia nigra. Nature 184: $1509-1510$.

Winzeler, H. B., and G. Belfort. 1993. Enhanced performance for pressure-driven membrane processes: the argument for fluid instabilities. J. Membr. Sci. 80: 35-47.

Zeman, L. J., and A. L. Zydney. 1996. Microfiltration and Ultrafiltration: Principles and Applications. Dekker, New York. 